\title{
Prevalence of Chronic Pain and Its Association with Depression in Adult Patients Referring to Health Centers in Yazd
}

\section{ART I C L E I N F O}

\section{Article Type}

Descriptive Study

\section{Authors}

Heidari Gh.A. ${ }^{1} P h D$,

Tavafian S.S.* PhD

\section{A B S T R A C T}

Aims CP (Chronic pain) is a common problem that substantially impairs physical and psychological health and economic well-being. The aim of the present study was to c determine the prevalence of chronic pain and its association with depression in over 30-years-old clients referring to health centers.

Instruments \& Methods This descriptive study was conducted among 397 people from April to August 2015. The participants were the adults who came to governmental health centers in the province. These health centers were selected based on random sampling. Two health centers were located in Yazd and 4 were in the provincial cities DASS-21 (Depression, Anxiety, and Stress Scale) was used to measure depression and VAS (Visual Analog Scale) was used to measure chronic pain. Six psychologists with a master's degree collected the data. The results were analyzed using Chi-square test by SPSS 23 software.

Findings The prevalence of chronic pain was $66.8 \%$. The highest prevalence of knee pain was $41.3 \%$. The prevalence of depression was $67.5 \%$. The relationship between chronic pain as an independent variable and dependent variable depression was significant $(\mathrm{p}=0.029)$.

Conclusion The prevalence of patients with chronic pain is $66.8 \%$, and the prevalence of depression is reported $67.5 \%$. There is a relationship between chronic pain and depression.

Keywords Chronic Pain; Depression; Adults

\section{CIT A T I O N L IN KS}

[1] Prevalence and correlates of suicidal thoughts and suicide attempts in people prescribed pharmaceutical opioids for ... [2] Chronic pain in the Japanese communityprevalence, characteristics and impact on ... [3] Relationship between depression and coping strategies in chronic back ... [4] Ethnic differences in the association between depression and chronic pain: Cross sectional ... [5] Depression and pain comorbidity: A literature ... [6] Chronic pain and comorbid mental health conditions: Independent associations of posttraumatic stress disorder and depression with pain, disability, and ... [7] Association of traumatic brain injury with chronic pain in Iraq and Afghanistan veterans: Impact of comorbid mental health ... [8] The relationship between chronic pain, social support, and depression in ... [9] Pilot feasibility study of a brief, tailored mobile health intervention for depression among patients ... [10] Understanding the link between depression and ... [11] Longitudinal associations between depression, anxiety, pain, and pain-related disability in chronic pain ... [12] Observing the effects of mindfulness-based meditation on anxiety and depression in chronic pain ... [13] The effectiveness of acceptance and commitment therapy (ACT) on the rate of chronic pain and pain catastrophizing in women with chronic low ... [14] The roles of pain coping strategies in adjustment to chronic ... [15] Comparing the role of psychological ... [16] Validation of depression anxiety and stress scale (DASS-21) for an ... [17] The depression anxiety stress scales (DASS): Normative data and latent structure in a large ... [18] Effects of music therapy on anxiety, stress and depression of patients undergoing ... [19] Correlation between visual analogue scale and short form of McGill questionnaire in patients with chronic low ... [20] Chronic pain, depression, and quality of life: Correlations and predictive value of ... [21] Depression: An important factor associated with disability among patients with chronic low ... [22] Comorbidity of chronic pain \& depression and its treatment ... [23] Self-reported depression, anxiety and evaluation of own pain in clinical sample of patients with different location ... [24] Exploring the relationship between spirituality, coping, and ... [25] Integrating psychosocial and behavioral interventions to achieve optimal rehabilitation ...

\section{Article History}

Received: September 21, 2017

Accepted: December 9, 2017

ePublished: April 30, 2018 


\section{Introduction}

Chronic pain (CP) is recognized as a public health problem that affects the general population physically, psychologically, and socially [1, 2]. CP is a common problem that substantially impairs physical and psychological health and economic well-being [2]. The prevalence of depression is higher in people with $\mathrm{CP}$ than in society [3].The prevalence of chronic pain was $40 \%$ and the incidence rate of chronic depression and chronic pain was $11 \%$ in England at the same time [4]. The incidence of pain in depressed patients at different time rates ranged from $15 \%$ to $100 \%$ (mean prevalence, $65 \%$ ) [5].

Many studies have shown that chronic pain is associated with depression [6, 7]. Chronic pain has been predictive of depression [8]. In a study, for more than half of the patients, chronic pain was a positive result of screening for depression $[9,10]$.

In other studies, depression had an impact on the severity of chronic pain [10, 11]. The concurrence of these 2 diseases has been confirmed in some studies [4]. Cognitivebehavioral interventions have been effective in patients with chronic pain and depression [9].

Cognitive interventions such as mindfulness, acceptance, and commitment lead to better recovery in these patients $[12,13]$.

Many studies in the field of chronic pain showed that the high prevalence of psychological factors (anger, depression, and anxiety) is related to the perception and attitude of the sufferer towards pain, coping strategies, and environmental, social, and cultural behaviors. In sum, the process of adjustment of people with chronic pain and how it responds to it has a major role [14].

Cognitive distortions, such as catastrophic disorder, feelings of helplessness, how patients evaluate pain, how they control it, how to interpret patients from the pain and its outcome, and generally the cognitive system, and beliefs associated with pain with depression [15]. The importance of this issue in the prevention and treatment of these two diseases, which affects one another, is felt.

Therefore, in order to determine the effects of these two diseases on each other, this study was conducted to with the aim of determining the prevalence of chronic pain and its association with depression in over 30 -yearsold clients referring to health centers.

\section{Instrument and Methods}

This descriptive cross sectional study was conducted from April to August 2015. The calculation of the sample size was calculated based on the statistic formula. The samples were determined 382, and 400 samples were considered reliable. Three incomplete questionnaires were deleted. The participants were the adults who came to governmental health centers in Fars province. These health centers were selected based on random sampling. Two health centers were located in Yazd and 4 were in the provincial cities.

Standard DASS-21 (Depression, Anxiety, and Stress Scale) was used to obtain depression and VAS (Visual Analog Scale) was used to measure chronic pain.

The DASS-21 was prepared in 1995 by Lawebond and Lawebond. This scale has 2 forms. The short form has 21 terms; psychological structure evaluates "depression", "anxiety", and "stress" by 7 different phrases. Its long form consists of 42 sentences, measuring each of the 14 phrases. A short form of 21 phrases was validated for the Iranian population [16]. Crawford and Henry in a sample of 1,771 people in England compared this tool with 2 other tools for depression and anxiety, and compared it with Cronbach's alpha for 0.95 anxiety, 0.90 depression, and 0.97 for total scores [17]. In Iran, the reliability of the research (Cronbach's alpha) was 0.94 in depression, 0.92 in anxiety, and 0.82 in stress [18]. The DASS-21 has the ability to diagnose and test signs of anxiety, depression, and stress during the past week. The scale is applicable for adults.

The pain measurement questionnaire is the most widely used pain measurement tool in the world. In addition to its reliability and validity, its advantage is its simplicity. This questionnaire is a 10-degree scale, with the left side of the zero number, indicating no pain and the right side of the 10 represents the most severe pain [19].

The data were collected by 6 psychologists with master's degree. The volunteer and free- 
of-charge clients completed the questionnaire, and those who were depressed at this scale were advised to go to the psychiatrist.

The results were analyzed using Chi-square test by SPSS 23 software.

\section{Findings}

A total of 397 people participated in the study. The mean age of participants were $61.52 \pm 11.52$, ranging between 31 and 87 years. Among the participants, $70.3 \%$ were female and $29.7 \%$ were male. Among the participants, $75.3 \%$ were married, $21.2 \%$ were those whose wives had died, and 3.5\% were single. No case of divorce was reported. The place of residence was $77.3 \%$ in the city and $22.7 \%$ in the village. Most of the occupations were housewives (Table 1).

Table 1) Demographic characteristics of studied participants $(\mathrm{N}=397)$.

\begin{tabular}{lcc}
\multicolumn{1}{c}{ Variables } & Number Percent \\
\hline Job & 272 & 68.5 \\
Housewife & 18 & 4.5 \\
Employed & 33 & 8.5 \\
Self- employed & 31 & 7.8 \\
farmer & 43 & 10.8 \\
Retired & & \\
Literacy & 189 & 47.6 \\
Illiterate & 167 & 42.1 \\
Primary school & 28 & 7.1 \\
High school & 13 & 3.3 \\
Collegiate & & \\
Gender & 279 & 70.3 \\
Female & 118 & 29.7 \\
Male & & \\
Marital status & 14 & 3.5 \\
Single & 299 & 75.3 \\
Married & 84 & 21.2 \\
Widow & & \\
Location of residency & 307 & 77.3 \\
City & 90 & 22.7 \\
Village & & \\
\hline
\end{tabular}

The prevalence of chronic pain in patients referring to health centers showed that $66.8 \%$ have chronic pain. The highest incidence of knee pain in 164 cases $(41.3 \%)$ was reported (Table 2).

132 people were normal for depression $(33.2 \%)$, and the rest of the 265 patients (66.8\%) had a mild to severe depression (Table 3).

The relationship between chronic pain as an independent variable and dependent variable depression was significant $(\mathrm{p}=0.029)$.
Table 2) Frequency of different chronic pain in studied

\begin{tabular}{|c|c|c|}
\hline Variables & Number & Percent \\
\hline \multicolumn{3}{|l|}{ Chronic pain } \\
\hline Yes & 295 & 74.0 \\
\hline No & 102 & 26.0 \\
\hline \multicolumn{3}{|l|}{ Headache } \\
\hline Yes & 41 & 10.3 \\
\hline No & 356 & 89.7 \\
\hline \multicolumn{3}{|l|}{ Neck pain } \\
\hline Yes & 30 & 7.6 \\
\hline No & 367 & 92.4 \\
\hline \multicolumn{3}{|l|}{ Shoulder pain } \\
\hline Yes & 30 & 7.6 \\
\hline No & 367 & 92.4 \\
\hline \multicolumn{3}{|l|}{ Hand pain } \\
\hline Yes & 49 & 12.3 \\
\hline No & 348 & 87.7 \\
\hline \multicolumn{3}{|l|}{ Low back pain } \\
\hline Yes & 49 & 12.3 \\
\hline No & 348 & 87.7 \\
\hline \multicolumn{3}{|l|}{ Abdomen pain } \\
\hline Yes & 7 & 1.8 \\
\hline No & 390 & 98.2 \\
\hline \multicolumn{3}{|l|}{ Hip pain } \\
\hline Yes & 13 & 3.3 \\
\hline No & 384 & 96.7 \\
\hline \multicolumn{3}{|l|}{ Knee pain } \\
\hline Yes & 164 & 41.3 \\
\hline No & 233 & 58.7 \\
\hline
\end{tabular}

Table 3) Frequency of depression among studied patients health centers $(\mathrm{N}=397)$.

\begin{tabular}{lcc}
\multicolumn{3}{c}{ patients health centers $(\mathrm{N}=397)$. } \\
\hline \multicolumn{1}{c}{ Depression rate } & Number & Percent \\
\hline No depression & 132 & 33.2 \\
Mild depression & 73 & 18.4 \\
Moderate depression & 106 & 26.7 \\
Severe depression & 51 & 12.8 \\
Very severe depression & 35 & 8.8 \\
\hline
\end{tabular}

\section{Discussion}

The aim of this study was to determine the prevalence of chronic pain and its relationship with depression in adult patients in health centers in Fars province. The results of this study showed that the prevalence of patients with chronic pain was $66.8 \%$. The prevalence of depression was reported $67.5 \%$. Although the relationship between these 2 diseases is two-way, in this study, the relationship between chronic pain as an independent variable and dependent variable depression was significant. The significance of these 2 diseases is very high in terms of which one causes another.

In various studies, the prevalence of these 2 diseases has been reported high. In 2003, the prevalence of major depressive disorder in patients with chronic pain was $52 \%$ [20]. But, 
in this study, a higher prevalence was found. The 2 diseases are debilitating. The World Health Organization has remarked that depression will be the second illness to be disabled by 2020. On the other hand, disability is higher in patients with chronic low back pain and depression [21].

For the causal relationship between chronic pain and depression, 5 main hypotheses have been raised: first, the "hypothesis", in which chronic depression has occurred, the second is the "hypothesis of the outcome," that depression is the result of chronic pain. The third hypothesis "label hypothesis" is that when a depression occurs, a person is prone to chronic pain. The fourth hypothesis is "cognitive mediation", in which psychological factors, such as weak coping strategies, have a cross-correlation between depression and chronic pain. The fifth hypothesis is "independent hypothesis", in which depression and chronic pain are shared by some mechanisms and are both separate diseases [22].

In a study, $63 \%$ of depression and $54 \%$ of anxiety were found in patients with chronic pain and the highest level of depression and anxiety for back pain and lowest for headache [23]. But, in this study, knee pain was the most common pains $(41.3 \%)$ and the lowest pain was abdominal pain (1.8\%). This study does not investigate race; racial differences can be meaningful in terms of psychological, social, and cultural characteristics. In a study conducted in Japanese and American patients with low back pain, significant differences were found between race and psychological and social components [24].

A person's cognitive characteristics can also be a predictor of depression in patients with chronic pain. People with negative thinking and generally catastrophic thoughts are susceptible to the treatment of their illnesses and those suffering from diseases; including chronic pain were less likely to be improved in due time through usual treatment. The catastrophe in people who have a sense of pain involves magnification and fear, and is followed by behavioral thoughts that avoid movement and activity. The results of the catastrophic thoughts show that catastrophic thoughts are associated with $40 \%$ of depression [25].
The limitation of the present study was the self-report signs of depression. Another limitation of the study was that some of the individuals identified as severe depression required the psychiatrist to confirm their depression.

Although this study has some strong points, some limitations such as self reporting of pain and depression by the patients may interfere the results of the study. Furthermore, this study is a cross sectional research which could not find the certain relationship between chronic pain and depression.

\section{Conclusion}

The majority of the patients are suffering from chronic pain accompanied with depression and chronic pain and depression are related to each other.

Acknowledgements: The authors of this study acknowledge all the patients who took part in this study. Furthermore, the authors would like to thank the research deputy of Tarbiat Modares University for the financial support of the study.

Ethical Permissions: No ethical approval code was reported by the authors.

Conflict of Interests: There is no conflict of interest for this study.

Authors' Contribution: Heidari Gh.A. (First author), Introduction author/ Original researcher/ Statistical analyst (60\%); Tavafian S.S. (Second author), Methodologist/ Discussion author (40\%).

Funding: Tarbiat Modares University supported this study which was a part of PhD thesis.

\section{References}

1- Campbell G, Bruno R, Darke S, Shand F, Hall W, Farrell M, Degenhardt L. Prevalence and correlates of suicidal thoughts and suicide attempts in people prescribed pharmaceutical opioids for chronic pain. Clin J Pain. 2016:32(4):292-301.

2- Inoue S, Kobayashi F, Nishihara M, Arai YC, Ikemoto T, Kawai T, et al. Chronic pain in the Japanese communityprevalence, characteristics and impact on quality of life. PLoS One. 2015;10(6):e0129262.

3- Rezaei S, Afsharnejad T, kafi M, Soltani R, Fallahkohan $\mathrm{S}$. Relationship between depression and coping strategies in chronic back pain patients. Daneshvar. 2009;16(81):63-74. [Persian]

4- Nicholl BI, Smith DJ, Cullen B, Mackay D, Evans J, Anderson J, et al. Ethnic differences in the association 
between depression and chronic pain: Cross sectional results from UK Biobank. BMC Fam Pract. 2015;16:128.

5- Bair MJ, Robinson RL, Katon W, Kroenke K. Depression and pain comorbidity: A literature review. Arch Intern Med. 2003;163(20):2433-45.

6- Outcalt SD, Kroenke K, Krebs EE, Chumbler NR, Wu J, $\mathrm{Yu} \mathrm{Z}$, et al. Chronic pain and comorbid mental health conditions: Independent associations of posttraumatic stress disorder and depression with pain, disability, and quality of life. J Behav Med. 2015;38(3):535-43.

7- Seal KH, Bertenthal D, Barnes DE, Byers AL, Strigo I, Yaffe $\mathrm{K}$, et al. Association of traumatic brain injury with chronic pain in Iraq and Afghanistan veterans: Impact of comorbid mental health conditions. Arch Phys Med Rehabil. 2017;98(8):1636-45.

8- Owen KL. The relationship between chronic pain, social support, and depression in college athletes. Capella University; 2015.

9- Ahmedani BK, Crotty N, Abdulhak MM, Ondersma SJ. Pilot feasibility study of a brief, tailored mobile health intervention for depression among patients with chronic pain. Behav Med. 2015;41(1):25-32.

10- Linton SJ, Bergbom S. Understanding the link between depression and pain. Scand J Pain 2011;2(2):47-54.

11- Lerman SF, Rudich Z, Brill S, Shalev H, Shahar G. Longitudinal associations between depression, anxiety, pain, and pain-related disability in chronic pain patients. Psychosom Med. 2015;77(3):333-41.

12- Rod K. Observing the effects of mindfulness-based meditation on anxiety and depression in chronic pain patients. Psychiatr Danub. 2015;27(Suppl 1):S209-11.

13- Irandoost F, Neshat doost HT, Nadi MA, Safary S. The effectiveness of acceptance and commitment therapy (ACT) on the rate of chronic pain and pain catastrophizing in women with chronic low back pain. J Res Psychol Health. 2014;8(3):31-40. [Persian]

14- Asghari A, Golak N. The roles of pain coping strategies in adjustment to chronic pain. Clin Psychol Personal. 2005;1(10):1-23. [Persian]

15- Vowles KE, McCracken LM. Comparing the role of psychological flexibility and traditional pain management coping strategies in chronic pain treatment outcomes. Behav Res Ther. 2010;48(2):141-6.

16- Sahebi A, Asghari MJ, Salari RS. Validation of depression anxiety and stress scale (DASS-21) for an Iranian population. Dev Psychol. 2005;1(4):36-54. [Persian]

17- Crawford JR, Henry JD. The depression anxiety stress scales (DASS): Normative data and latent structure in a large non-clinical sample. Br J Clin Psychol. 2003;42(Pt 2):111-31.

18- Moradipanah F. Effects of music therapy on anxiety, stress and depression of patients undergoing cardiac catheterization. Tehran: Tarbiat Modares University; 2005. pp. 42-8. [Persian]

19- Rezvani Amin M, Siratinayer M, Abadi A, Moradyan T. Correlation between visual analogue scale and short form of McGill questionnaire in patients with chronic low back pain. Qom Univ Med Sci J. 2012;6(1):31-4. [Persian]

20- Elliott TE, Renier CM, Palcher JA. Chronic pain, depression, and quality of life: Correlations and predictive value of the SF-36. Pain Med. 2003;4(4):331-9. 21- Hung CI, Liu CY, Fu TS. Depression: An important factor associated with disability among patients with chronic low back pain. Int J Psychiatry Med. 2015;49(3):187-98.

22- Singh TB, Dash A, Haldar P. Comorbidity of chronic pain \& depression and its treatment outcome: A review. J Dent Med Sci. 2015;14(2):32-4.

23- Makovec MR, Vintar N, Makovec S. Self-reported depression, anxiety and evaluation of own pain in clinical sample of patients with different location of chronic pain. Zdr Varst. 2015;54(1):1-10.

24- Wachholtz AB, Pearce MJ, Koenig H. Exploring the relationship between spirituality, coping, and pain. J Behav Med. 2007;30(4):311-8.

25- Sullivan MJ, Feuerstein M, Gatchel R, Linton SJ, Pransky G. Integrating psychosocial and behavioral interventions to achieve optimal rehabilitation outcomes. J Occup Rehabil. 2005;15(4):475-89. 